\title{
HEPATITIS DUE TO THE INJECTION OF HOMOLOGOUS BLOOD PRODUCTS IN HUMAN VOLUNTEERS ${ }^{1}$
}

\author{
BY JOHN R. NEEFE, ${ }^{2}$ JOSEPH STOKES, JR., JOHN G. REINHOLD, 2 AND \\ F. D. W. LUKENS \\ (From the School of Medicine and Hospital of the University of Pennsylvania, Philadelphia)
}

(Received for publication June 28, 1944)

It is now recognized that human whole blood, plasma, or serum may occasionally contain an agent, or agents, capable of producing hepatocellular jaundice when administered parenterally to susceptible persons ( 1 to 4 ). Thus far, the only method of detecting the presence of this agent in such materials is by testing them in human volunteers. The present studies in human volunteers, which were initiated by the occurrence of jaundice in a case previously described (3), have yielded further information concerning certain aspects of this disease. This report presents the methods employed and the initial results obtained in the study of 9 additional cases of experimentally induced hepatitis. The literature pertaining to serum jaundice has been adequately reviewed elsewhere (1 to 3 ).

\section{METHODS}

Volunteers. Nine white male volunteers between the ages of 18 and 25 were selected on the basis of the following criteria: (a) No significant medical history or physical abnormalities. (b) Normal blood count, urinalysis, serological test for syphilis, and erythrocyte fragility. (c) Normally functioning gall bladder as indicated by cholecystography. (d) No evidence of hepatic disturbance detectable by a group of liver function studies. During the period of investigation, the volunteers acted as attendants at a nearby hospital where their duties were mildly to moderately strenuous. The diet consisted of the ordinary hospital fare and seemed to be adequate. Risk of an epidemic of jaundice as a result of contact with the volunteers was considered minimal because of the apparent absence of contact infection in the jaundice outbreak (U. S. Army 1942) related to the serum component of yellow fever vaccine (4). A few cases of jaundice had occurred among the patients of this institution during the year before this study was begun, but no case was subse-

1 This investigation was conducted under the Commission on Measles and Mumps, Board for the Investigation and Control of Influenza and Other Epidemic Diseases in the Army, Preventive Medicine Service, Office of the Surgeon General, U. S. Army, Washington, D. C.

Captain, M.C., A.U.S.

- Principal Biochemist, Philadelphia General Hoepital. quently observed, among the hospital population of approximately 6000 patients and 590 employees, until after the experimentally induced disease had appeared in the volunteer group, when 2 of the employees developed jaundice (see below).

One of the volunteers (H. J. C.) had a history of jaundice 4 years prior to this study, but the other 8 had no history of jaundice. Several had attended patients with jaundice during the preceding year. The volunteers were observed for 1 to 3 weeks before inoculation and none showed evidence of hepatic dysfunction during this period.

Procedure. After obtaining a specimen of plasma for preservation in the frozen state, the volunteers were inoculated with one of several suspected materials in order to determine the presence of an icterogenic agent. They were then studied, at frequent intervals, by means of a group of liver function tests so as to detect the earliest evidence of hepatic disturbance. As soon as this appeared, the men were hospitalized.4 Plasma or serum, stools, bile, nasopharyngeal washings, and urine, to be used in future experiments, were collected during the pre-icteric and icteric stages.

The materials used for inoculation were as follows: 1. Plasma $A$-pooled convalescent mumps plasma, obtained in April 1942 from a group of 14 soldiers of the U. S. Army, stationed in this country, during their convalescence from mumps. The blood was collected in bottles containing sodium citrate as an anticoagulant; the plasma was removed, cultured, and frozen. The routine cultures were negative. In June 1942, a civilian with mumps was treated with this plasma and 76 days later developed jaundice (3). The plasma was considered responsible for transmission of the icterogenic agent and was withheld from further usage. When used in this study, it had been preserved in the frozen state for approximately 18 months. Previous studies had shown that this material was not icterogenic for a large number of animals $(5,6) .2$. Plasma $B$-obtained from volunteer B. C. during mild hepatitis, 23 days after his inoculation with plasma $A$. The blood was collected in a bottle containing sodium citrate as an anticoagulant; the plasma was removed, cultured, and frozen. The cultures were negative. The plasma was used in this study 1 and 2 months after collection. 3. Yellow fever vaccine (lot No. 335)-This vaccine was one of the lots associated with the occurrence of jaundice in the U. S. Army in 1942 (4). The pooled human serum in this vaccine has been regarded as the

\footnotetext{
- Medical Clinic, Hospital of the University of Pennsylvania, Philadelphia.
} 
carrier of the icterogenic agent. This vaccine was prepared in November 1941 and was dispensed under vacuum, in the desiccated state in sealed ampoules. It had been kept at a low temperature until June 1942, but from that time until used in this study in November 1943, it had been kept at room temperature in Washington, D. C. It was prepared for injection in accordance with the standard directions, i.e., the suspension of dried contents of 1 ampoule in $55 \mathrm{ml}$. of physiological salt solution. In March 1944, intracerebral inoculation of mice showed that the yellow fever virus in this vaccine was no longer capable of producing the disease."

Special studies. (Normal ranges listed herein are based on the preinoculation studies of the inoculated group.) A. Blood: The serum bilirubin concentration was measured by the method of Malloy and Evelyn (7). The normal range for this group was found to be between 0.2 and 1.4 mgm. per $100 \mathrm{ml}$. and the level in the same normal person occasionally varied as much as $0.7 \mathrm{mgm}$. The bilirubin excretion test (8) was used initially because of its reputed value as one of the most sensitive indicators of hepatic dysfunction in the absence of jaundice. The results, to be reported elsewhere, were inconsistent and apparently subject to random influences to such an extent that the test was discontinued. The Van den Bergh reaction was determined by the ring test. The cephalin-cholesterol flocculation test was performed according to the technic of Hanger (9). While valuable information was obtained by this test, the results could not be accepted with the same assurance as those of certain other tests, owing to the frequent occurrence of 1 and 2 plus reactions in normals. Readings at 48 hours presented greater difficulties in this respect than did those at 24 hours; the results shown, therefore, are the 24-hour readings. In addition to this, technical difficulties have lowered our confidence in the procedure. Differences in sensitivity of the antigen extend to vials bearing the same lot number and purchased at the same time. Duplicate tests set up in different laboratories by careful and experienced workers, using the same reagents, of ten failed to agree completely. ${ }^{\circ}$ It is evident that the procedure must be standardized with considerable care and controlled by frequent determinations on normal sera. If this is done, the test is capable of providing helpful data. The fractional cephalin-cholesterol flocculation test proposed by Bruger (10) gave abnormal results in some dilutions in all normal controls, and was therefore abandoned. Mirsky and Von Brecht (11) have reported similar experiences with this fractional test. Serum total protein, albumin, and globulin concentrations were determined by

- Courtesy of Dr. Werner Henle, Assistant Professor of Bacteriology in Pediatrics, School of Medicine, University of Pennsylvania.

- Recent studies have shown that discrepancies obtained in the results of tests set up in 2 different laboratories are due, in large part, to variation in the amount of light to which the serum-antigen mixtures are exposed. When kept in the dark or in subdued light, the results are more uniform and fewer false positives are obtained (Science, $1944,100,83)$. the biuret photoelectric method of Kingsley (12). The preinoculation range for this group was: Total protein 6.9 to 8.2 ; albumin 5.0 to 6.0 ; globulin 1.6 to 2.6 grams per $100 \mathrm{ml}$. Total and esterified serum cholesterol levels were estimated by the method of Reinhold (13) and the range was: Total-158 to $286 \mathrm{mgm}$. per $100 \mathrm{ml}$., esters-95 to $161 \mathrm{mgm}$. per $100 \mathrm{ml}$., or 50 to 76 per cent of the total. Serum alkaline phosphatase was measured by the method of Bodansky adapted to the photoelectric colorimeter (14). The range before inoculation was from 1.5 to 3.4 Bodansky units. Prothrombin activity was determined by the method of Quick (15). Before inoculation it varied between 70 and 100 per cent of normal. Vitamin $A^{7}$ was estimated in blood plasma by the method of Kimble (16) which is based on the Carr-Price reaction. The results have been expressed in International Units, calculated according to Kimble's directions. Facilities for this determination were not available at the beginning of the investigation, so that preinoculation levels could not be established. However, estimations were made in several cases before the onset of hepatitis and these results probably approach the preinoculation level. Sedimentation rates were determined by the Wintrobe technic (17). The range before inoculation was from 3 to $15 \mathrm{~mm}$. per hour. Erythrocyte fragility was measured by the method of Waugh and Asherman (18). The procedure proved to be satisfactory, but the solutions were found to change in $\mathrm{pH}$ on standing, so that considerable time and effort were expended on the necessarily frequent checks of the reagents. Routine blood counts were performed periodically throughout the study. "Target" cells.(19) were sought in the ordinary blood smears. Bromsulphalein test-the dose used was $5 \mathrm{mgm}$. per $\mathrm{kgm}$. and the amount of retention was measured 30 minutes after the injection. The retention in this group before inoculation never exceeded 5 per cent. $B$. Urine tests: The diazo spot test of Godfried and the Harrison spot test (Godfried modification) (20) were employed routinely for the detection of bilirubin in the urine. The methods were quite satisfactory, although weakly positive results were infrequently obtained in normal individuals. In such cases, however, subsequent tests were negative. The methylene blue test of Franke (21) was discarded because of the frequent occurrence of false positive reactions. The "foam test" for bilirubin was quite insensitive compared to the diazo and Harrison spot tests. Urobilinogen - the test of Wallace and Diamond (22) was used routinely and none of this group had a positive test in the 1:10 dilution before inoculation. The method of Watson (23) was used at less frequent intervals because of difficulties in the collection of the required 24-hour urine specimens. Bile acids were sought by the method of Hay (24). It was realized that a negative test did not exclude the presence of bile acids. Routine urinalyses were performed periodically throughout the investigation. The intravenous hippuric acid test was performed according to the technic recommended by Quick (15). The dose

\footnotetext{
7 Courtesy of Dr. Charles Urbach, Children's Hospital; Associate in Pediatrics, School of Medicine, University of Pennsylvania.
} 
was 1.77 grams of sodium benzoate. Just before the injection, $400 \mathrm{ml}$. of water were ingested. The preinoculation range for the group was from 0.64 to 0.94 grams of benzoic acid excreted in the urine as hippuric acid in 1 hour. C. Miscellaneous tests: A cholecystogram was obtained on each volunteer before inoculation. The oral methods involving the use of either Priodax or tetraiodophenolphthalein were employed. Serologic tests included those for syphilis, typhoid, paratyphoid A and B, brucellosis, the Weil-Felix reaction, and heterophile antibodies. ${ }^{8}$ Serologic studies for leptospira icterohemorrhagica were negative. Duodenal drainage was carried out in a few cases during the icteric stage according to the usual technic. The histamine test of Klein (25) was frequently employed. It was inferior to the determination of serum bilirubin concentration, but would undoubtedly be helpful where this procedure is not available. The water excretion test was performed according to the technic suggested by Lichtman (26); namely, by measurement of the hourly urinary output for 4 hours after the ingestion of $1000 \mathrm{ml}$. of water. A normal adult should excrete the ingested amount within the 4-hour period. It was found, however, that a number of normals excreted abnormal amounts according to this interpretation (473 to $1290 \mathrm{ml}$.). The test was therefore abandoned.

Interpretation of results of special studies. The result of any one test was considered abnormal when it deviated beyond the preinoculation range of the group. In a few cases, results. not beyond the range of the group, but deviating significantly from many determinations before and after inoculation in the same subject, were regarded as abnormal. As temporarily abnormal results with single tests were occasionally observed in the control group, hepatic disturbance was not considered to be present in the inoculated men unless more than one test was abnormal.

Control studies. In order to determine the responses of uninoculated normal persons to the repeated performance of a group of liver function tests, studies were made on 10 men who were quartered with the volunteers, 10 men living elsewhere, and on a laboratory technician connected with this investigation. Special effort was also made to carry out such studies on the controls during incidental minor illnesses, i.e., upper respiratory infections, gastrointestinal upsets, and "grippe." The tests included, in all cases, determinations of serum bilirubin, urine bilirubin, and cephalin flocculation; in some cases, bromsulphalein excretion, serum protein, plasma vitamin A, prothrombin activity, and total and esterified cholesterol were also determined. It was not possible to study all of the control group as frequently or completely as was done in the case

We are indebted to the William Pepper Laboratory of Clinical Medicine of the University of Pennsylvania for these studies.

- Agglutination tests were done through the courtesy of Dr. E. L. Stubbs, Professor of Veterinary Pathology of the University of Pennsylvania; complement-fixation tests by Dr. F. Boerner, Associate Professor of Clinical Bacteriology, Graduate School of Medicine, University of Pennsylvania. of the volunteers. However, several of the controls were studied at frequent intervals over periods of 4 to 10 weeks.

\section{RESULTS}

Incidence of hepatitis. The incidence of hepatitis following the inoculation of 9 human volunteers is shown in Table I. To the first group of

TABLE I

Results of inoculation of human volunteers

\begin{tabular}{|c|c|c|c|c|c|}
\hline \multirow{2}{*}{$\begin{array}{c}\text { Icterogenic } \\
\text { material }\end{array}$} & \multirow{2}{*}{$\begin{array}{l}\text { No. } \\
\text { inoc. }\end{array}$} & \multirow{2}{*}{$\begin{array}{l}\text { Hepatitis } \\
\text { with } \\
\text { overt } \\
\text { jaundice }\end{array}$} & \multicolumn{2}{|c|}{$\begin{array}{c}\text { Hepatitis without } \\
\text { overt jaundice }\end{array}$} & \multirow{2}{*}{$\begin{array}{l}\text { Negative } \\
\text { results }\end{array}$} \\
\hline & & & Definite & Probable & \\
\hline $\begin{array}{l}\text { Plasma A } \\
\text { Plasma B } \\
\text { Yellow fever vac- } \\
\text { cine, lot } 335\end{array}$ & $\begin{array}{l}6 \\
2 \\
2\end{array}$ & 5 & $\begin{array}{l}2 \\
1\end{array}$ & 1 & $\begin{array}{l}0 \\
0 \\
0\end{array}$ \\
\hline
\end{tabular}

5 volunteers, who were inoculated intravenously with varying amounts of Plasma $\mathrm{A}$, has been added the case of the patient (3) who received this plasma as an experimental therapeutic measure in 1942, making a total of 6 . Of these, 5 developed hepatitis with jaundice. The remaining one (W. D. S., Figure 5) did not have indisputable evidence of hepatitis. However, he did have several brief episodes characterized by gastrointestinal symptoms and slightly abnormal results with the tests used to detect hepatic disturbance. Because these abnormalities were similar to those experienced by others of the group who later developed hepatitis, this case has been classified as probable mild hepatitis without jaundice. Two volunteers were inoculated intravenously with Plasma B. Both developed symptoms and laboratory manifestations of mild hepatitis without jaundice. Two volunteers were inoculated subcutaneously with $2 \mathrm{ml}$. of the yellow fever vaccine. One developed hepatitis with jaundice, and the other, hepatitis without overt jaundice. ${ }^{10}$ The incidence of successful experimental transmissions of this disease was, therefore, 100 per cent. In an attempt to determine if immunity was conferred by 1 attack of this disease, 1 volunteer (R. R. M.) was reinoculated, with the same dose of the same material by the same route, 1 month after all signs of

\footnotetext{
${ }^{10}$ Serum obtained from both men 3 weeks following inoculation and examined by Dr. Max Theiler showed no neutralizing antibodies against the yellow fever virus.
} 
the previous hepatitis had disappeared. During the $\mathbf{1 4 0}$ days that have elapsed since the second inoculation, no signs of hepatitis have been detected. Additional experiments of this type are now in progress.

Course of disease. The course of the disease in each of the volunteers is portrayed by the data charted in Figures 1 to 9. Mild symptoms and signs, usually occurring from 12 to 35 days after inoculation, marked the onset of the disease. This was followed by an asymptomatic interval or by periodic recurrences of mild symptoms and signs which, after 73 to 110 days, usually culminated in the familiar clinical picture of an acute hepatitis with jaundice. The course thereafter was similar to that observed in mild infective hepatitis. ${ }^{11}$ For this reason, the main interest has centered about the long interval between inoculation and jaundice. As no evidence of hepatic dysfunction was detected in any of the volunteers prior to inoculation, abnormal results with more than one liver function test have been regarded as an indication of hepatic disturbance due to the inoculation. In this report, such a disturbance is referred to as hepatitis, since studies have shown that the pathologic picture, at least during the icteric stage, is that of hepatitis $(27,28)$. When interpreted on this basis, the charts show that hepatitis was present long before it was manifested by jaundice. In some cases, the process seemed to be active continuously during the interval between the onset of the disease and the development of jaundice, whereas in others, it appeared to be active intermittently. For purposes of discussion, it has been convenient to consider the course of the disease in 2 periods; an early period, which includes the first 60 days after inoculation, and a late period, which covers the interval beyond 60 days. Based on this arbitrary division, Table II shows the time of onset, in each volunteer, of the early and late manifestations of hepatitis. From these data, it is seen that the onset occurred during the first

1 The term infective hepatitis is used here to include both the sporadic and the epidemic types of infective hepatitis. So-called sporadic and epidemic catarrhal jaundice, epidemic hepatitis, and infectious hepatitis or jaundice are other terms which are used in the literature more or less synonymously with infective hepatitis.
TABLE II

The time of onset of the early and late manifestations of hepatitis

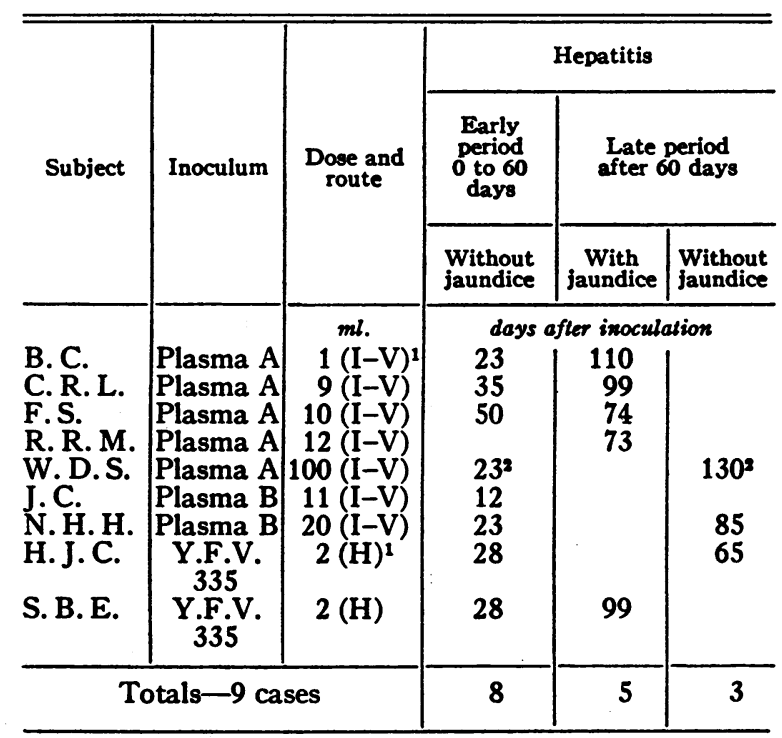

1 (I-V)-Intravenous; (H)-Subcutaneous.

2 Slight abnormalities have been regarded as probable hepatitis.

50 days in 8 of the 9 cases, and in 7 of these, it appeared between the 12 th and 35 th days. In 1 man (J. C.), manifestations of the disease were observed in only the early period; in 7, however, they occurred during both the early and late periods. In only 1 case (R. R. M.) did jaundice occur during the late period without preceding signs of hepatitis during the early period. In 4 cases (F. S., C. R. L., S. B. E., B. C.), jaundice did not occur for $24,69,71$, and 87 days, respectively, after the first evidences of the disease had been detected. Furthermore, overt jaundice did not appear in 4 cases (W. D. S., J. C., N. H. H., H. J. C.) during either the early or late periods, although 3 of them had definite, and the other suggestive, evidence of hepatitis in one or both of the periods. These cases clearly demonstrate the occurrence of hepatitis without jaundice, a possibility which has been previously suggested by others $(1,29$ to 32$)$. That the appearance of hepatitis during the early period has not been confined to our series alone is suggested by 2 cases, previously reported (2); in which hyperbilirubinemia was first observed 3 and 5 weeks, respectively, after inoculation, and by the quoted statement of one of Cameron's volunteers (30): 
B. C.
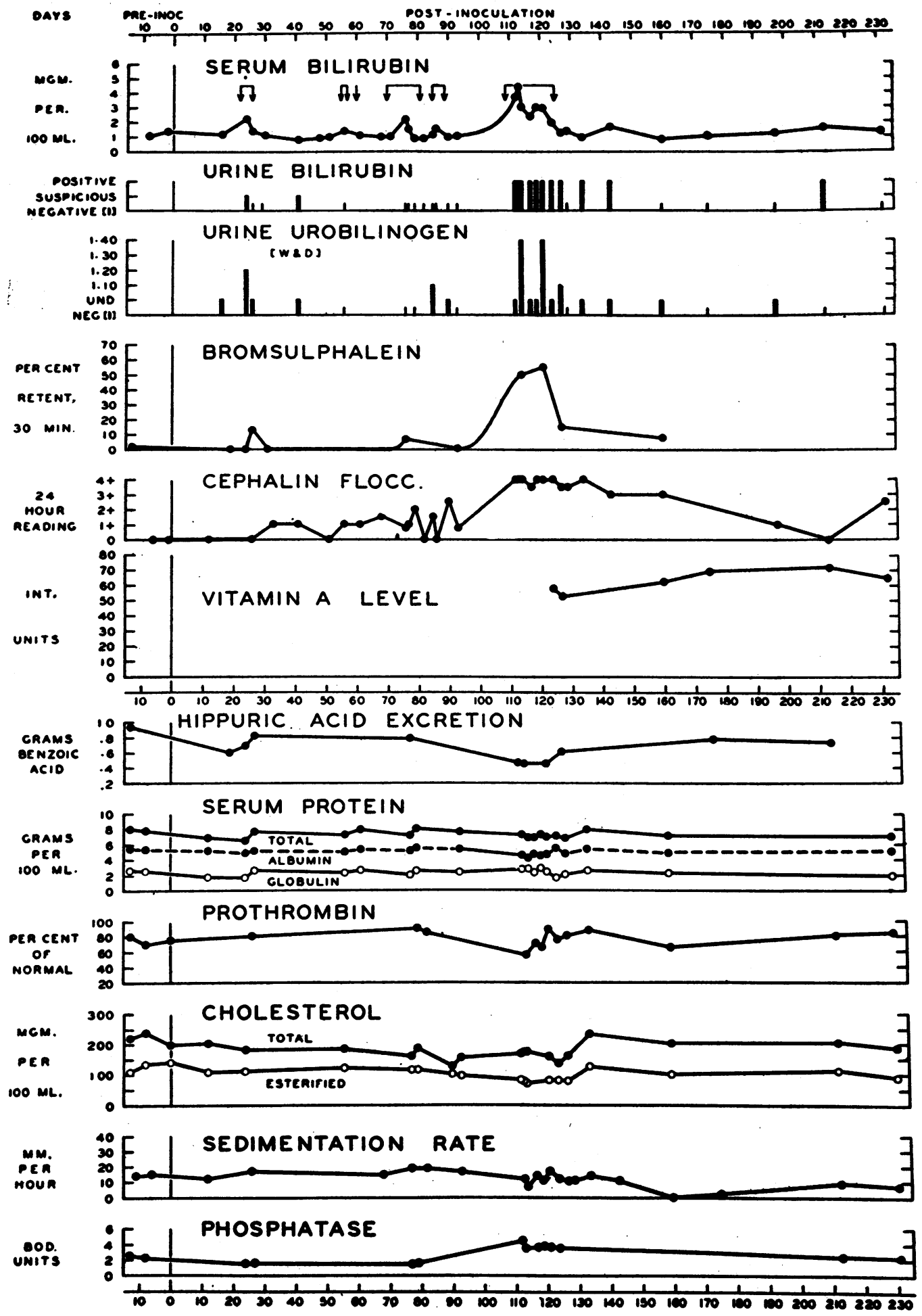

Fig. 1. Laboratory Studies Before and After the Inoculation of B. C. with 1.0 ML. Of Plasma A Intravenously

In all figures, the arrows, above the curves for serum bilirubin, indicate days when symptoms occurred. 


\section{C.R.L.}
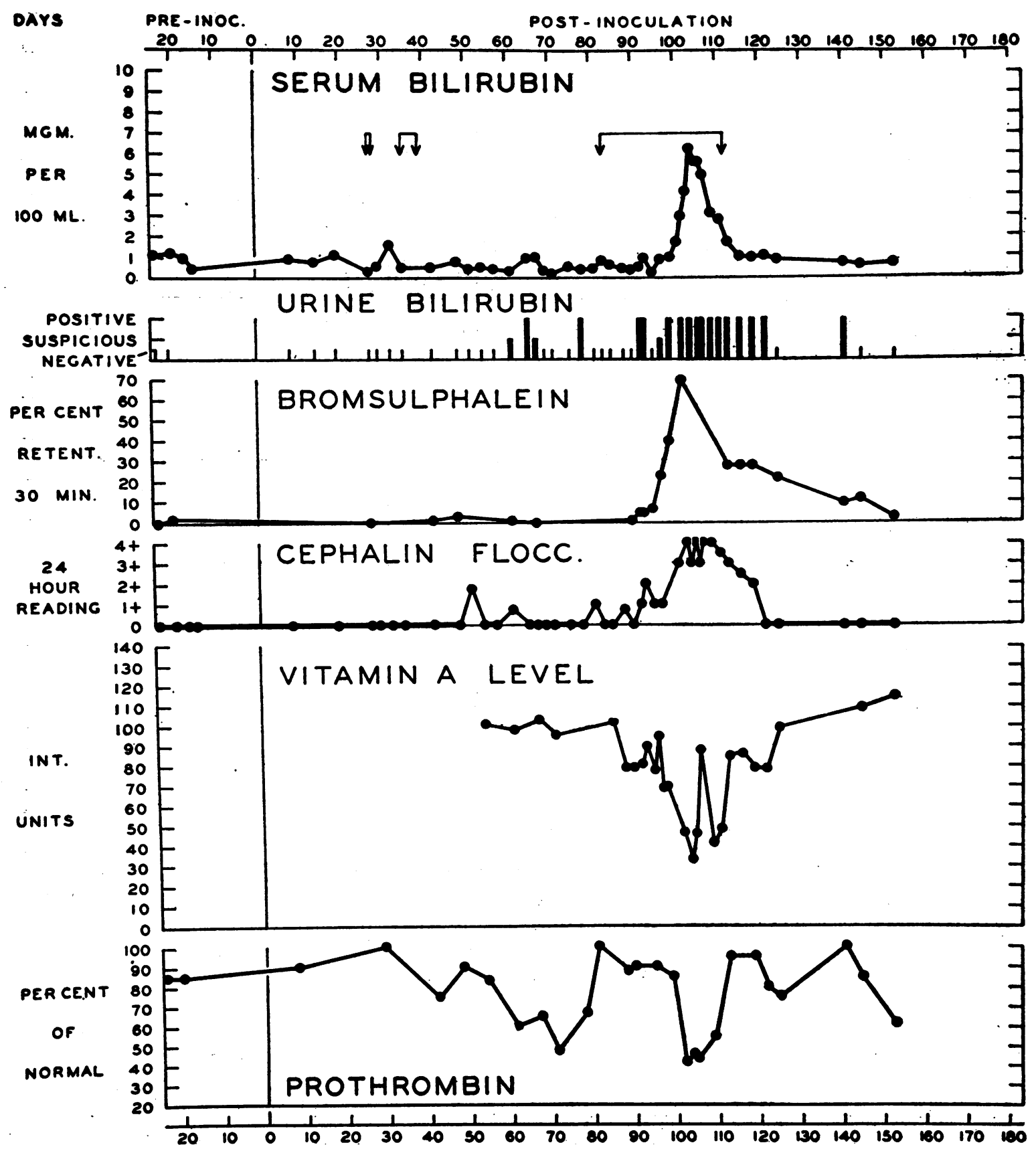

Fig. 2. Studies Before and After the Intravenous inoculation of C. R. L. with 9.0 ML. Of Plasma A 


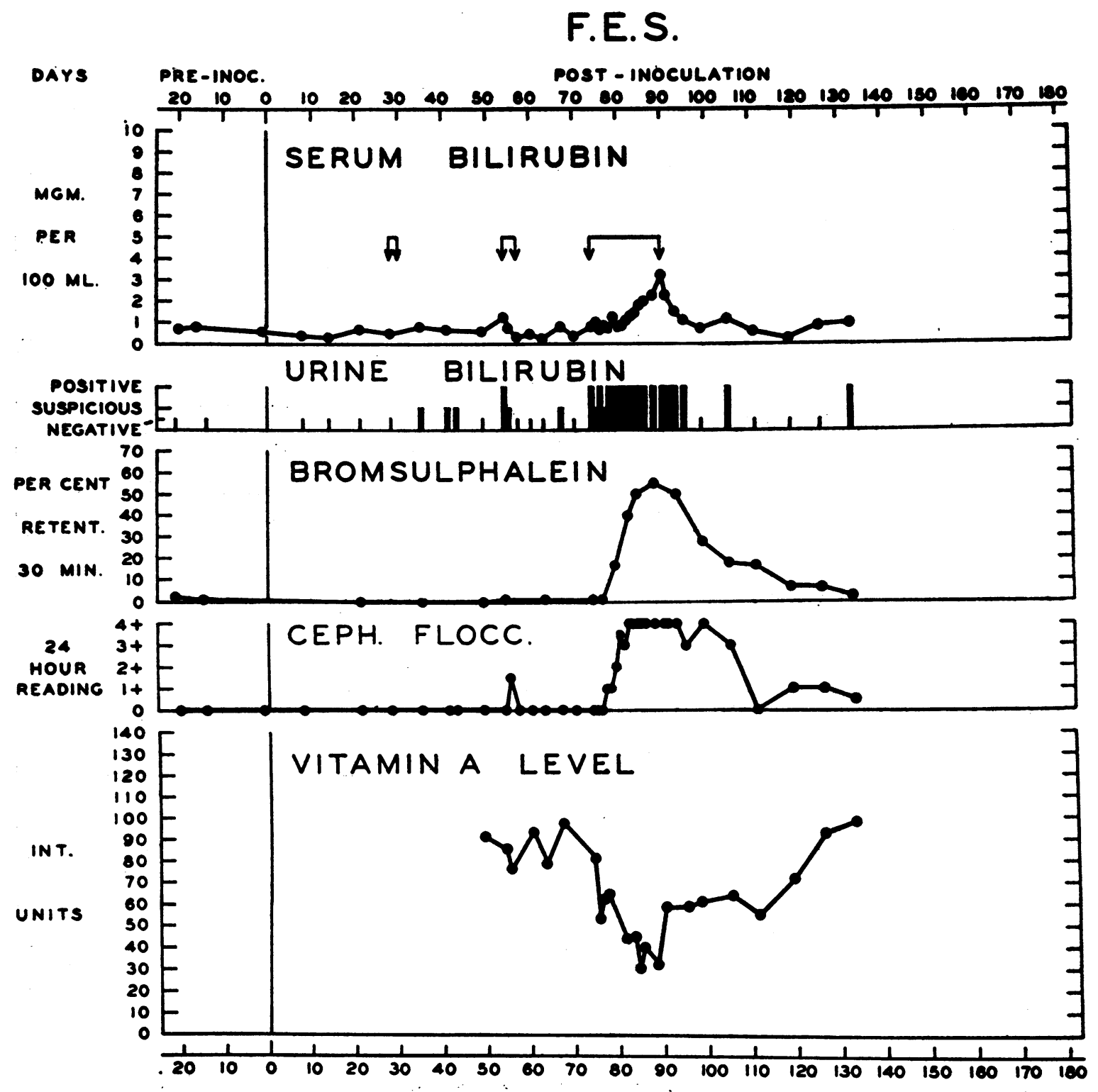

Fig. 3. Studies Before and After the Intravenous inoculation of F. E. S. with 10.0 ML. Of Plasma A

"A month after the injection I felt out of sorts and passed dark urine. I saw the regimental medical officer, but there was no need for hospital. I stuck it out well during the hard marches of the campaign, but just when it was over (nearly 6 months after inoculation) I went and got jaundice." It is apparent from these results that the onset of the disease is probably much earlier than has been recognized. Previous estimations of the incubation period have been based on the inoculation-to-jaundice interval, which has commonly been 60 to 100 days (1, 2, 33). On that basis, most of our cases had a similar incubation period. However, since the incubation period is defined as the interval between the entrance of an infective agent and the first manifestations of the disease (34), the true incubation period in most of our cases was 12 to 


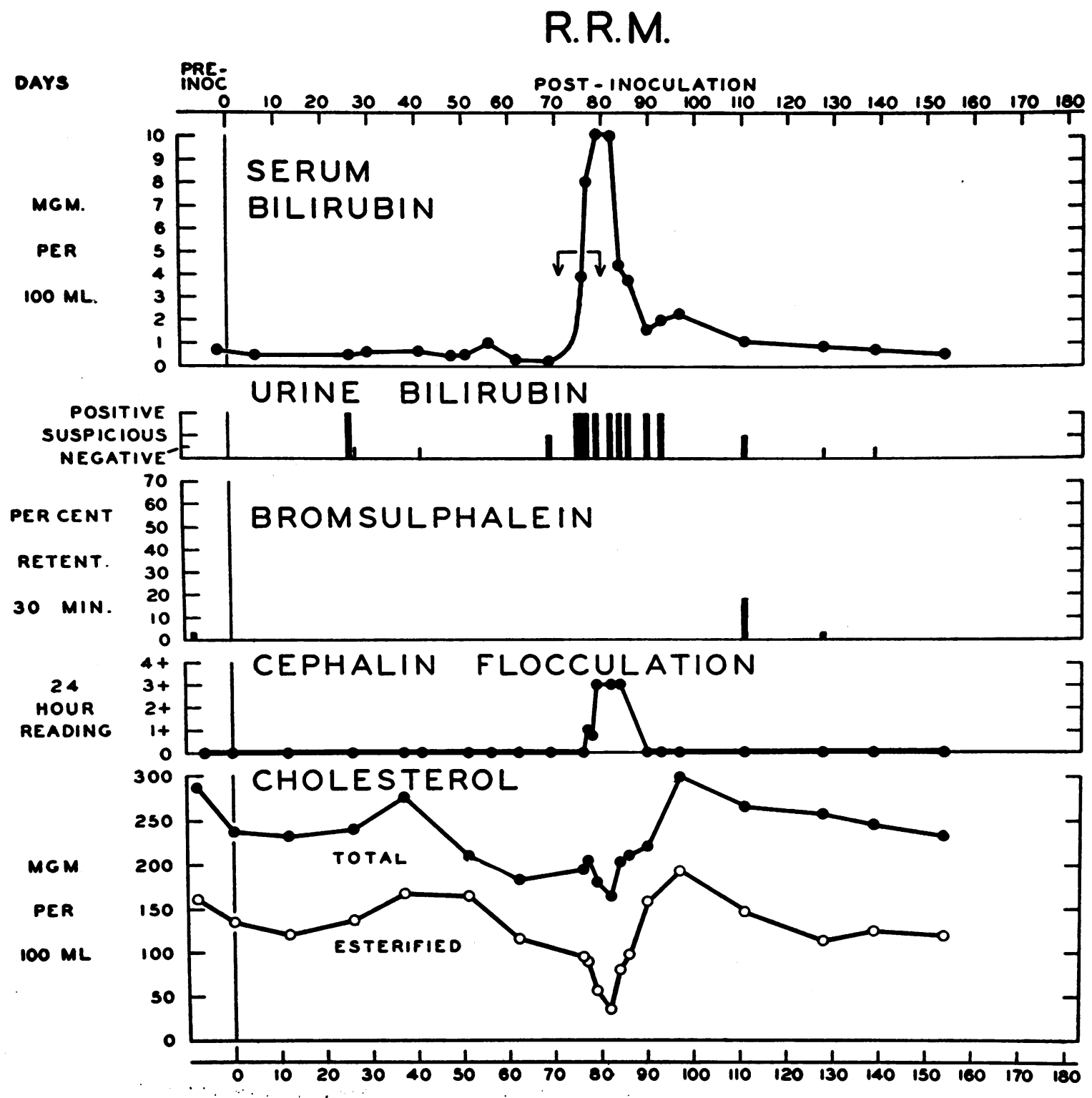

Fig. 4. Stúdies Before and After the Intravenous Inoculation of R. R. M. with 12.0 ML. OF Plasma A

As only 3 bromsulphalein tests were performed, columnar charting has been used. Vitamin A determinations were not done on R. R. M.

35 days, an interval which approximates the incubation period of those forms of infective hepatitis unrelated to serum.

The symptoms and signs of the hepatitis that occurred during the early period were variable. The symptoms included malaise, weakness, anorexia, nausea, vomiting, muscular pains, and headache. Examination showed no consistent findings and jaundice was never observed. Slight fever was occasionally present but the temperature reached $102^{\circ} \mathrm{F}$. in only 1 case (B. C.). Tenderness could usually be elicited on first percussion over the liver, but its edge was seldom palpable during this stage. The spleen was palpable in only 1 case (B. C.). These symptoms and signs usually disappeared after 1 to 


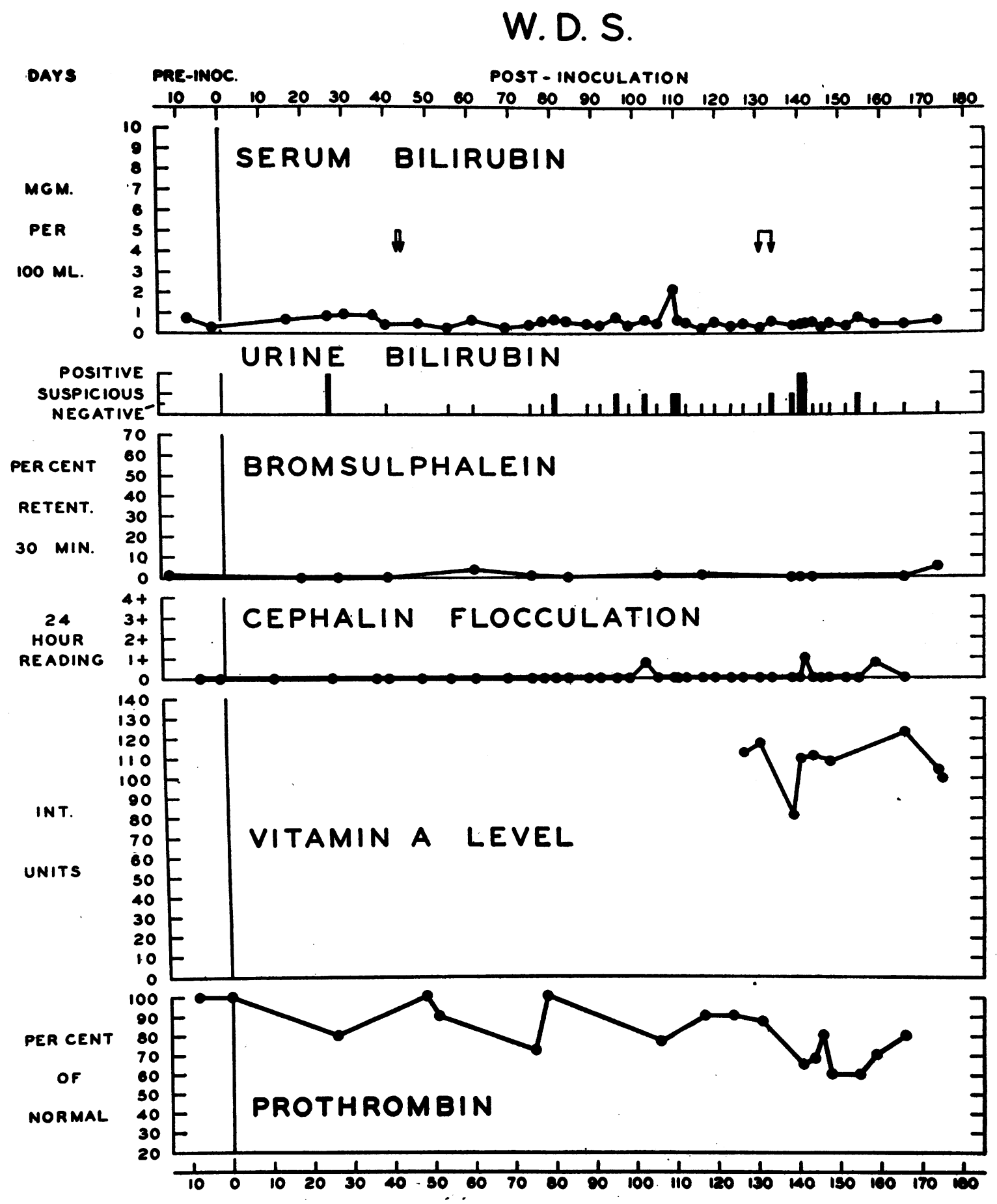

Fig. 5. Studies Before and After the Intravenous Inoculation of W. D. S. With 100.0 ML. Of Plasma A 


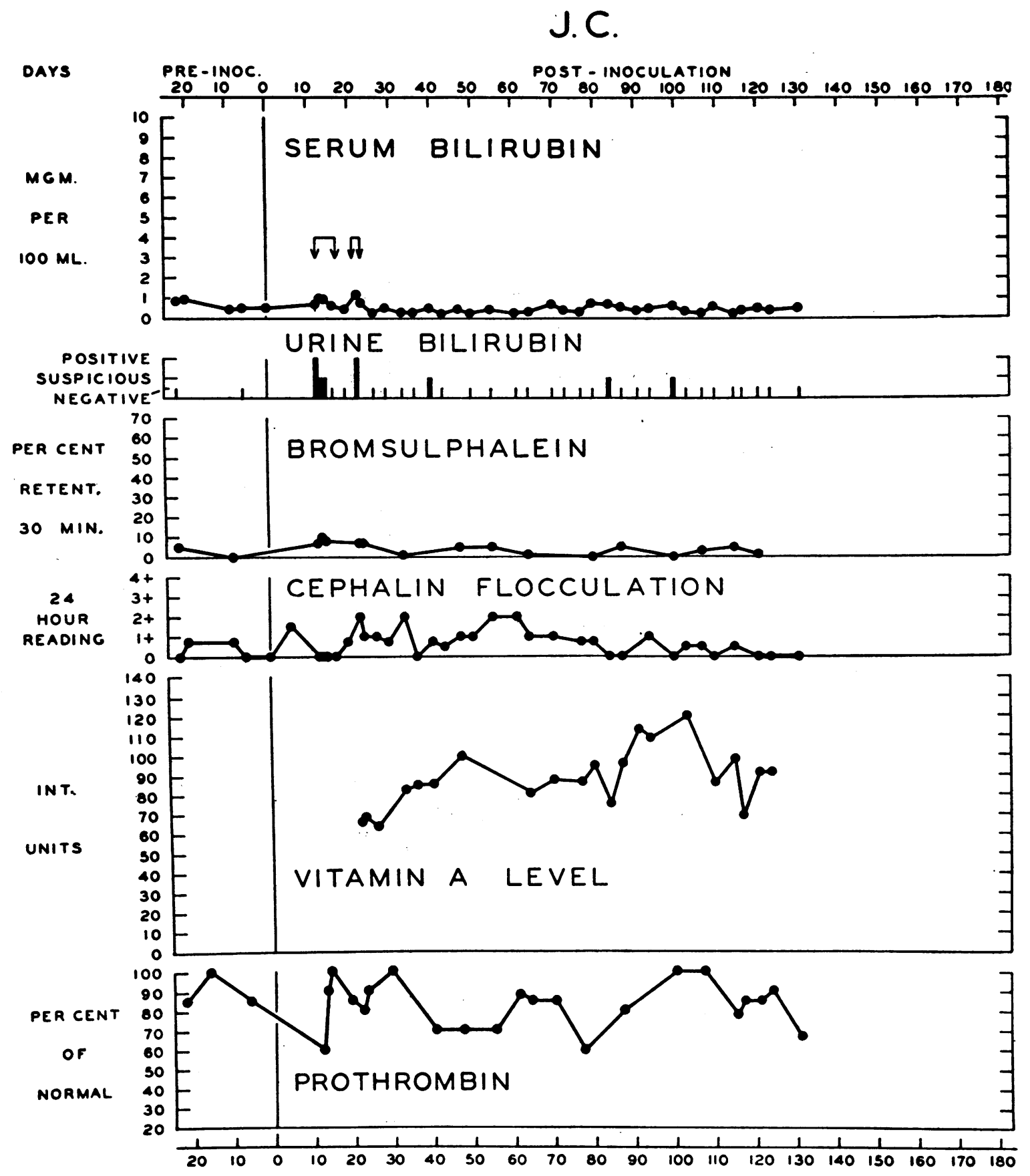

Fig. 6. Studies Before and After the Intravenous Inoculation of J. C. WITH 10.0 ML. OF PlasMa B

The sedimentation rate was increased (maximum, $25 \mathrm{~mm}$. per hour) from the 19th to the 36th days. 


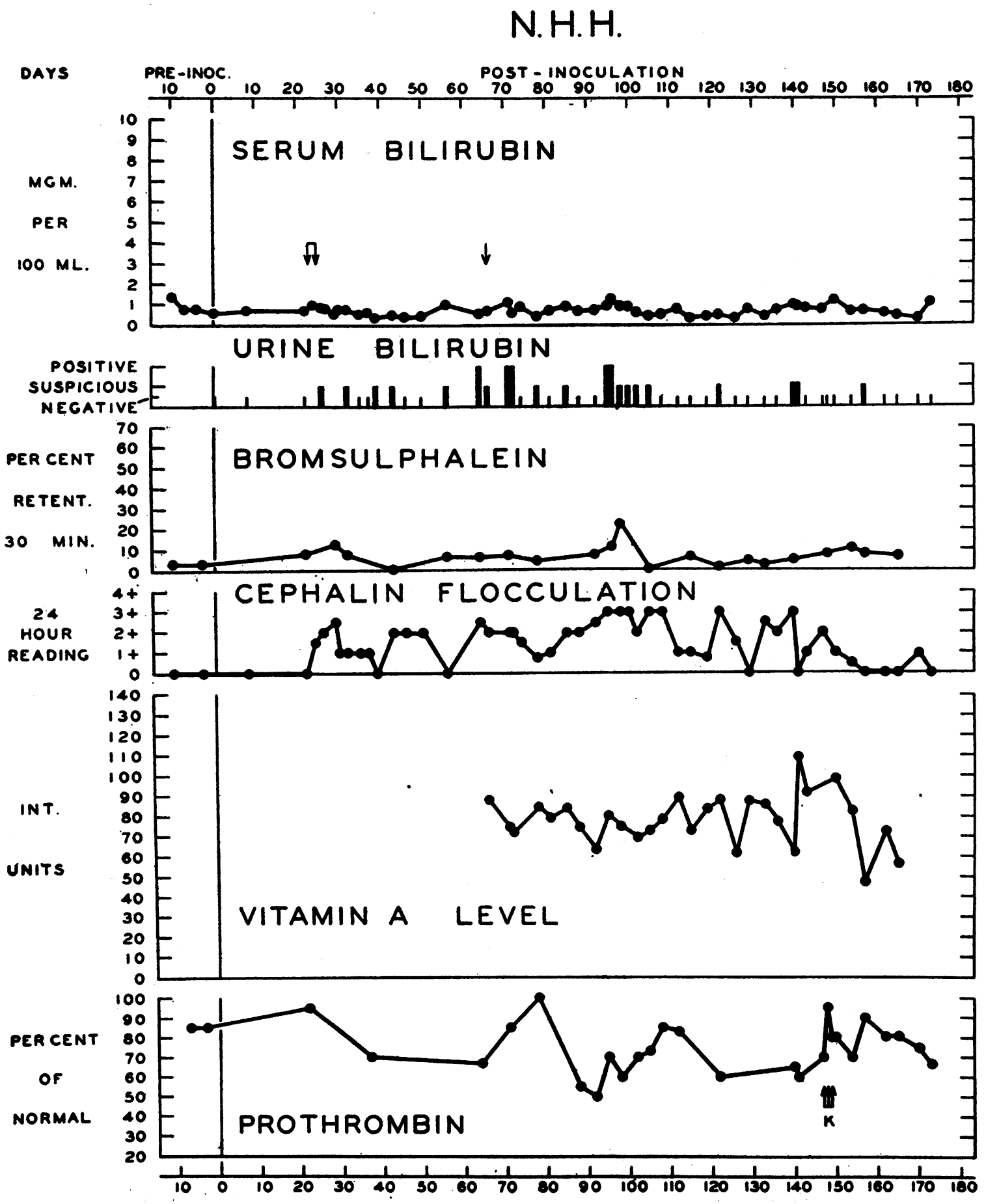

Fig. 7. Studies Before and After the Intravenous Inoculation of N. H. H. with 20.0 ML. Of Plasua B

The sedimentation rate was increased (maximum, $28 \mathrm{~mm}$. per hour) from the 29th to the 39th days. Arrows at $\mathrm{K}$ below the prothrombin curve indicate days when $\mathbf{5 . 0} \mathrm{mgm}$. of synkavite were given intravenously. 


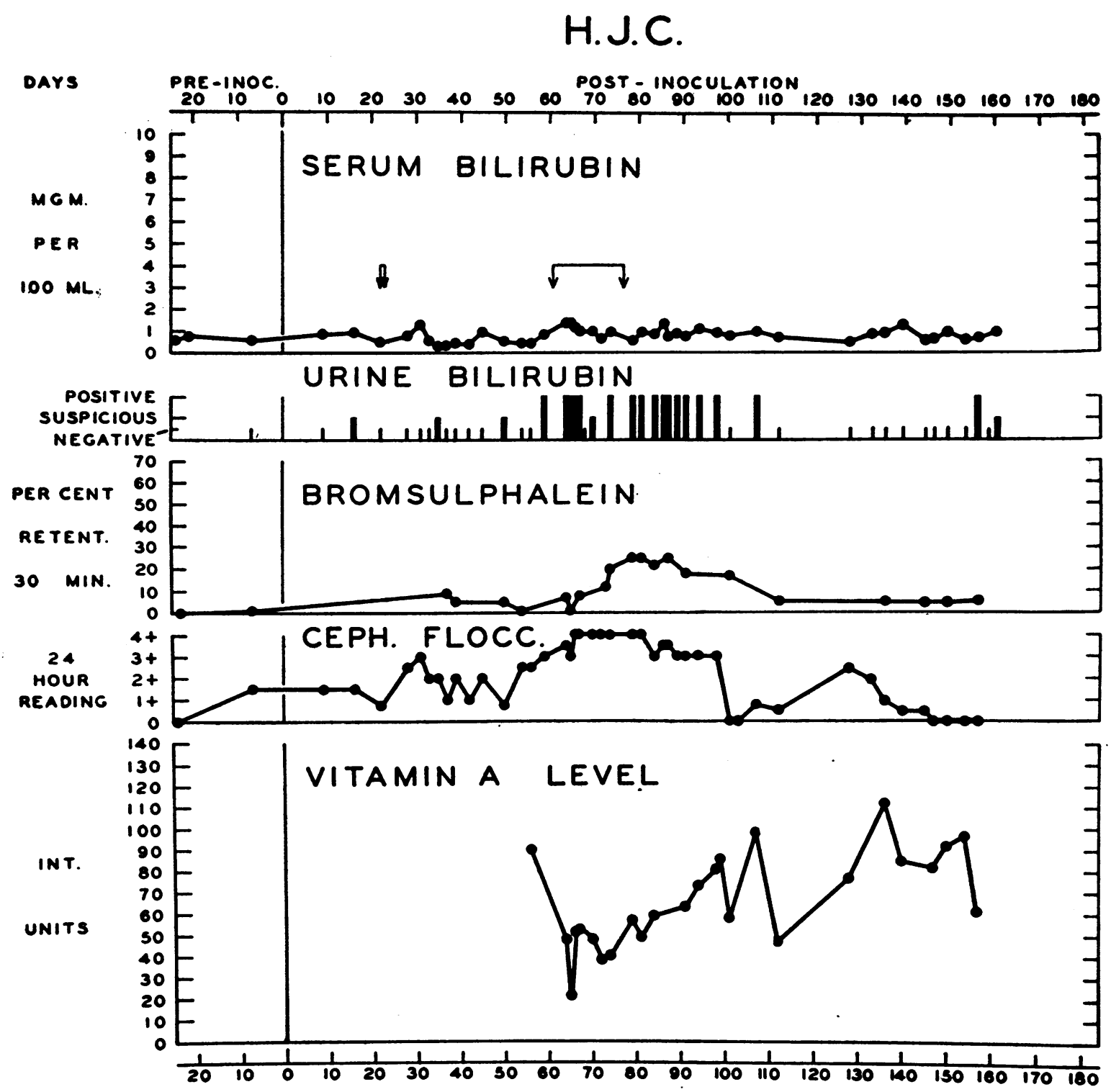

Fig. 8. Studies Before and After the Subcutaneous Inoculation of H. J. C. With 2.0 ML. OF Yellow Fever Vaccine

5 days, and the subsequent interval, prior to the development of the final stage of the disease, was either asymptomatic or marked by periodic recurrences of mild symptoms and signs. The occurrence of abnormal liver function tests during this period indicated that the symptoms and signs were due, at least in part, to hepatic disturbance. During the late period, the symptoms and signs were more severe and prolonged, and they did not differ from those described by others as occurring in the prodromal phase of serum jaundice $(1,2,4,33)$. They included anorexia (8 cases), nausea (8), weakness and fatigue (8), dark urine (6), abdominal discomfort or pain (6), vomiting (4), upper respiratory infection (4), sensation of fever (4), skin eruptions (3), headache (3), eructation (3), arthralgia or joint stiffness (2), myalgia (2), sore throat (2), chilliness (1), and diarrhea (1). The physical findings during this period were not unusual. 


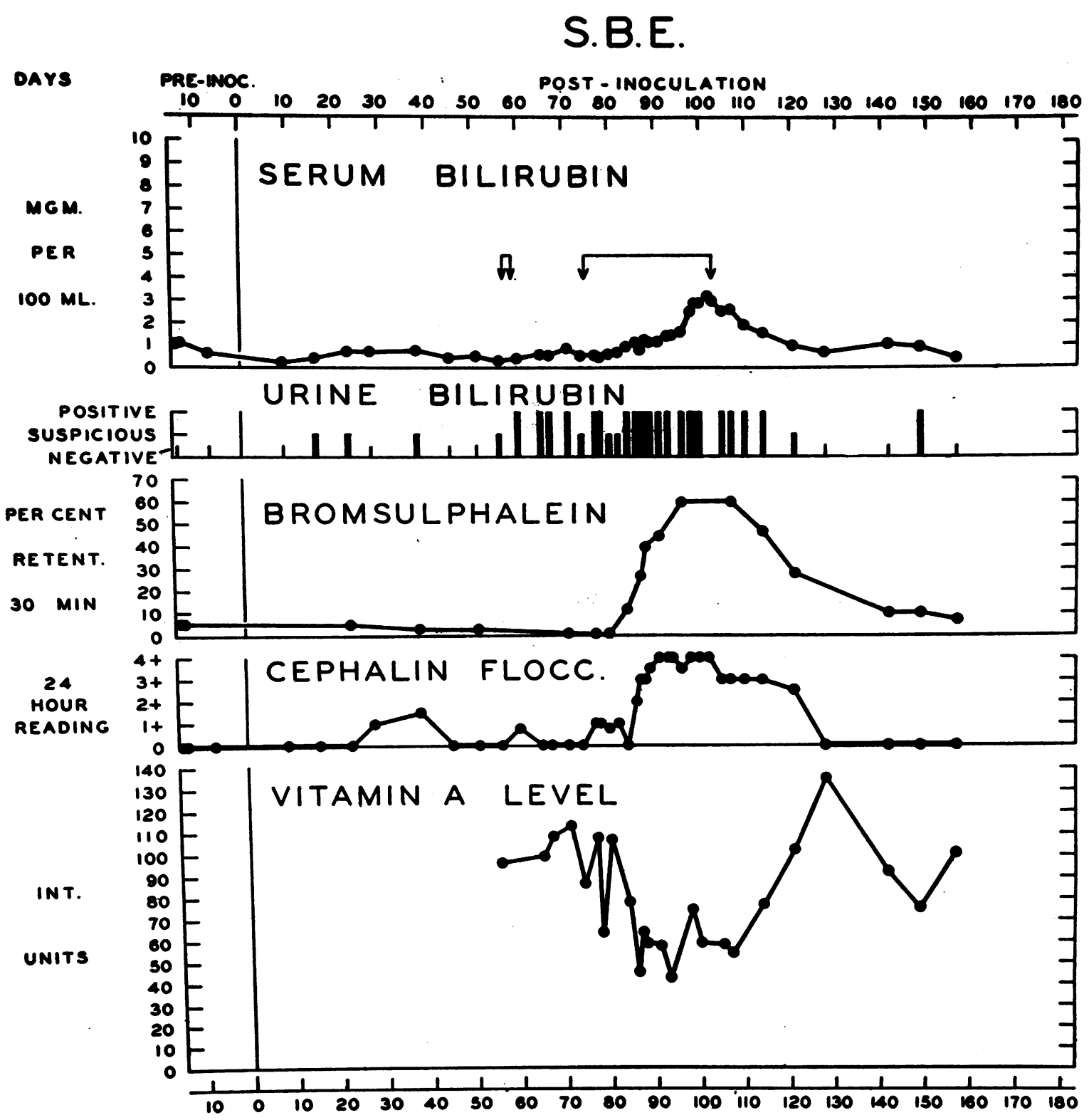

Fig. 9. Studies Before and After the Subcutaneous Inoculation of S. B. E. with 2.0 ML. OF Yellow Fever Vaccine

Overt jaundice was present in 5 cases. The liver was slightly enlarged and palpable for a brief period in most cases, but the spleen was palpable in only 1 (C. R. L.). The temperature was usually normal, although a few had occasional slight elevations. No hemorrhagic phenomena were observed. The cutaneous manifestations differed in the 3 cases. B. C. developed multiple pruritic lesions, similar to those of chronic ec- zema or urticaria, on both forearms, 40 days before the occurrence of overt jaundice, and these lesions persisted for 16 days. H. J. C. developed a macular erythematous rash over the ankles and lower legs 4 days before other evidence of acute hepatitis appeared. The lesions coalesced and the involved areas became fiery red. Swelling, local heat; and tenderness about the right ankle were associated. These phenom- 
W.F.A.

CONTROL

DAYS
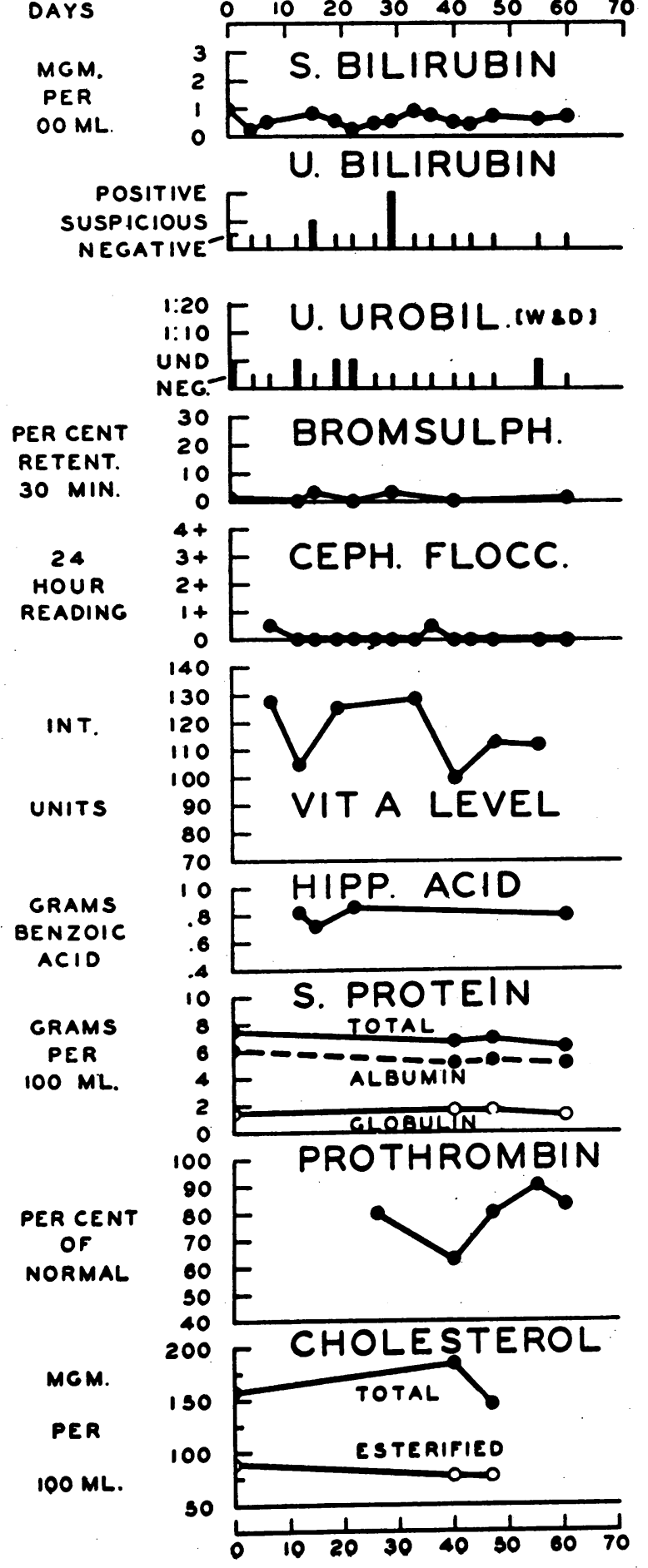

ena lasted for 9 days. F. S. developed severe generalized urticaria 4 days before other manifestations of hepatitis appeared, and these, together with associated swelling and pain in the joints of the knees, wrists, and hands, persisted for 6 days. Two of these 3 men had allergic histories and the other had had catarrhal jaundice 4 years before. The eruptions in all were suggestive of an allergic mechanism, and it seems possible that a sensitization to the agent or some one of its products may have resulted from its activity during the early period of the disease.

\section{LABORATORY OBSERVATIONS}

Most of the additional information concerning the course of this disease has been provided by the laboratory studies of hepatic function. Because of the minor and transient fluctuations in the results of the various tests in normal persons (Figure 10), the several preinoculation determinations have been of great value in the interpretation of the significance of small changes. The tests for serum bilirubin concentration, bilirubinuria, cephalin flocculation, bromsulphalein excretion, plasma vitamin $\mathrm{A}$, and prothrombin activity were found to detect hepatic disturbance more consistently and promptly than did the tests for urine urobilinogen, total serum protein, albumin and globulin concentrations, total and esterified cholesterol, serum alkaline phosphatase, hippuric acid excretion and sedimentation rate. The results of all these tests have been included in Figure 1 because the case history is presented in this report, and also because this subject was the source of Plasma B. Figures 2 to 9, however, include only those tests which provided the most pertinent information. Figure 10 shows the results of the studies on a normal individual over a period of 60 days.

It will be noted that bilirubinuria was among the first signs of hepatic disturbance (Figures 2, $3,6,9)$. Moreover, it sometimes appeared long before there was any significant increase in the

Fig. 10. Studies on an Uninoculated Control for a Period of 60 days

This individual worked and lived with the inoculated group. The only abnormal finding was the single positive urine bilirubin test. The fluctuations in vitamin $A$ and prothrombin were within normal limits. 
concentration of total serum bilirubin (Figures $2,3,9)$. In 1 case (Figure 9), bilirubinuria was the only definite finding that suggested activity of the disease during the symptom-free interval that immediately preceded the final stage of hepatitis with jaundice. The main disadvantage was the occasional finding of weakly positive tests in normals. The concentration of serum bilirubin showed transient slight elevations during the early period of the disease in some cases (Figures 1, 2, 3, 6, 8), but in others, no elevation was observed, although other tests revealed the presence of hepatic dysfunction during this period (Figures 7,9 ). In those cases that developed overt jaundice during the late period, the serum bilirubin occasionally did not increase until a week or more after considerable hepatic dysfunction had been demonstrated by other means (Figures 2, 3). In 3 cases (Figures 6, 7, $8)$, the concentration of serum bilirubin never exceeded the upper extreme of the normal range for the group, although other tests showed considerable abnormality of hepatic function. This test, therefore, was useful, but a normal result did not exclude the presence of hepatitis. The cephalin-cholesterol flocculation test was helpful in spite of the limitations which have been previously discussed. Positive results were obtained in all cases during some stage of the disease, although in W. D. S. (Figure 5) the significance was questionable. In 5 cases (Figures $1,6,7,8,9)$, it suggested continued activity of the process during the asymptomatic intervals that followed the onset of the disease. In 2 instances during the late period of the disease, however, other procedures revealed hepatic disturbance 1 to 3 days before it was indicated by a positive cephalin test (Figures 3,4 ). In only 1 case (Figure 1) was it the last test to return to normal after the final stage of the disease, negative results being obtained in other cases in which continued hepatic dysfunction was still revealed by bromsulphalein retention and bilirubinuria (Figures 2, 3,4,9). This is not surprising in view of the fact that the cephalin test is supposed to indicate only an active process. The bromsulphalein test proved to be a reliable and sensitive indicator of hepatic dysfunction, and in addition, it did not seem to be as subject to random influences as were many of the other procedures.
Abnormal retention was observed in 4 cases during the mild transient episodes of hepatic disturbance that occurred in the early period of the disease (Figures 1, 6, 7, 8), and retention was always found during the more severe stages. The test was among the first to indicate the onset of the late stage of the disease (Figures $2,3,8,9$ ), and was usually one of the last to return to normal (Figures 2, 3, 4, 8, 9), thus affording one of the best indices of recovery. It was especially valuable in the cases of hepatitis without jaundice (Figures $6,7,8$ ), and during the preicteric stage of cases which later developed jaundice. As jaundice was not severe in any of our cases, it was also used to advantage during the icteric stage. One man, B. C., developed a sensitivity to bromsulphalein after 7 injections, over a period of 4 months. This was first manifested by the occurrence of urticaria, 30 minutes after the injection. After the next injection, 1 week later, giant urticaria appeared within 5 minutes, and for this reason, the test was discontinued on this individual. Plasma vitamin $A$ determinations were not available throughout the entire period of this investigation, but the results thus far suggest that the procedure is a sensitive indicator of hepatic disturbance. Decreases in the vitamin A level were observed simultaneously with, and occasionally before, changes in the results of other tests (Figures 2, 3, 6, 8, 9). It has therefore been of considerable value in a study such as this in which the type of disease is known in advance. However, its fluctuation in many varied conditions (35) greatly diminishes its value as a diagnostic test for hepatic disturbance in undiagnosed illnesses. The determination of prothrombin activity was helpful in some cases (Figures 2, $5,6,7)$, but in one (S. B. E.), it showed no significant change during a period of marked hepatic dysfunction with jaundice. The other studies previously mentioned were of value only in a confirmatory or negative way. In a few instances, the tests for hippuric acid excretion (Figure 1), urine urobilinogen (W. D. S.; B. C., Figure 1), and sedimentation rate (N. H. H., J. C.) added support to the evidence of hepatic dysfunction when the significance of changes in the results of other procedures was uncertain.

It is apparent that no single test provides reliable information concerning the hepatic func- 
tional state at all times. A group of tests is therefore necessary, if mild hepatic disturbance is to be detected, and for this type of liver disease, the tests for serum bilirubin concentration, bilirubinuria, cephalin flocculation, bromsulphalein retention, plasma vitamin $A$ level, and prothrombin activity appear to be the most satisfactory.

The studies on the control group indicated that the tests for serum bilirubin, urine bilirubin, cephalin flocculation, plasma vitamin A, cholesterol esters, prothrombin activity, and sedimentation rate occasionally yielded abnormal results in normal persons (Figure 10) or during incidental minor illnesses, unrelated to hepatitis. However, such abnormalities were never found with more than one of these tests at the same time. One person had repeated studies during a 10-day gastrointestinal upset in which the symptoms were similar to those observed in the volunteer group in association with mild hepatitis. In this case, all the tests were repeatedly negative. On the basis of these observations, it has seemed justifiable to regard abnormal results with more than one liver function test as evidence of hepatic disturbance, presumably due, in these cases, to hepatitis.

\section{CASE REPORT}

A brief summary of the case of B. C. has been included to illustrate the varied phenomena that may be associated with this disease.

B. C. (Figure 1), age 22, after the control studies, was inoculated intravenously with $1.0 \mathrm{ml}$. of Plasma A. Twentytwo days after inoculation he developed generalized aches and pains, headache, marked anorexia, nausea, vomiting, weakness, malaise, and elevation of temperature to $102^{\circ} \mathrm{F}$. Examination revealed tenderness to fist percussion over the liver and a palpable spleen. Laboratory studies revealed an elevated serum bilirubin, retention of bromsulphalein, and increased urobilinogen in the urine. A number of "target cells" were observed in the blood smear. Plasma B was obtained from him on the 23rd day. Prompt recovery ensued and he was well until the 55th day when anorexia returned, and was associated with vomiting and loose stools. The cephalin cholesterol test was weakly positive $(1+)$. From the 60th to 76th day, the eruption described previously appeared on the forearms. From the 72nd to 80th day, malaise, anorexia, and sore throat were noted. The serum bilirubin rose on the 77th day (Figure 1), but promptly returned to normal.

On the 85th day, nausea, slight diarrhea, and vague persistent discomfort in the right lower abdomen occurred in association with focal tenderness in the right lower quadrant. The leukocyte count was 10,400 and temperature was $99.4^{\circ} \mathrm{F}$. The surgeon advised laparotomy because of possible appendicitis. At operation, the appendix was normal, but the lower ileum was diffusely inflamed and the mesentery edematous and studded with swollen, enlarged lymph nodes. Post-operative roentgen examination of the gastrointestinal tract revealed no abnormality.

On the 109th day, malaise, anorexia, nausea, and dark urine appeared, and were followed, on the 110th day, by jaundice. On the 114th day, he developed urticaria after injection of bromsulphalein. While still jaundiced, 118 to 123 days after inoculation, there was slight elevation of temperature and a moderately severe diarrhea. On the $126 t h$ day, roentgen examination of the gastrointestinal tract revealed an abnormal ileal pattern similar to that of regional ileitis, but the symptoms, by this time, had disappeared.

He was well after his discharge from the hospital on the $129 t h d a y$, and roentgen examination of the gastrointestinal tract on the 213th day showed marked improvement of the small intestinal pattern, although slight abnormality still persisted. On the 232nd day, he was in good health, but the cephalin test was still intermittently positive.

This case illustrates the occurrence of repeated manifestations of this disease before the development of jaundice. The demonstration of an acute ileitis and mesenteric adenitis at laparotomy is interesting in view of the post-mortem findings in the fatal cases of post-vaccinal hepatitis that occurred in the U. S. Army (1942). In these cases, acute inflammation and edema of various parts of the gastrointestinal tract were frequently observed (27). Symptoms of mild diarrhea and crampy abdominal pain, which in retrospect were probably due to this process, were experienced by B. C. intermittently throughout the pre-icteric and icteric periods. It seems likely that these symptoms and findings represent manifestations of a generalized disease in which only hepatitis is usually recognized. Apparently such findings have not previously been recorded as a manifestation of this disease except in autopsy material. Plasma B, obtained from this individual on the 23rd day, has been shown to contain the "hepatitis-producing" agent by the occurrence of a mild form of the disease in J. C. and N. H. H. following its injection.

\section{POSSIBLE CONTACT CASES}

Two hospital employees, who were housed separately from the volunteers and from each other, but who were in exceptionally close contact with one of the volunteers at a time when he was showing evidence of mild hepatitis, developed moderately severe jaundice within 1 to 3 months. The illnesses were typical of infective hepatitis (catarrhal jaundice). Both had moderate elevations of temperature $\left(102^{\circ} \mathrm{F}\right.$.) during the prodromal stage, and in this respect, their disease differed from that of the volunteers, in whom only slight elevations were observed. The absence of other contact cases among the large institutional group, and especially among the $\mathbf{8 7}$ men with whom the volunteers were quartered, indicated that there was little tendency for the experimentally produced disease to apread by 
ordinary contact. Because of the exposure of these 2 persons to the experimentally produced disease, and the absence of recognized exposure to other jaundiced patients or to each other, infection acquired from the volunteer remains a possibility. Propert (36) has previously recorded 2 cases of jaundice in which the infection appeared about 2 months after exposure to patients with measles serum hepatitis.

\section{DISCUSSION}

The fact that homologous blood products may contain an agent capable of producing hepatitis has been confirmed by the results of the inoculation of this group of men with plasma or yellow fever vaccine containing human serum. The high incidence ( 100 per cent) in this series is of interest in comparison with that reported by other investigators. Propert (36) recorded the occurrence of hepatitis in all of 7 children, each of whom received $4.5 \mathrm{ml}$. of one batch of convalescent measles serum, although a certain number of people elsewhere, receiving portions of the same batch of serum, did not develop hepatitis. Cameron (30) reported hepatitis in 86 per cent of 7 men inoculated with 1.0 to 2.0 $\mathrm{ml}$. of blood or serum from patients with infective hepatitis. The onset of the disease in some of his cases was delayed as long as 6 months, and as the work was done in an endemic area, he points out that the experiment was not performed under ideal conditions. Oliphant, Gilliam, and Larson (2), working with a much larger group, recorded an incidence of only 20 to 30 per cent among those experimentally inoculated. It is apparent that the high incidences of successful experimental transmission have been confined to smaller series. In addition to the size of the groups, however, one or more of the following factors may be related to the higher incidence in the present series as compared with that of Oliphant et al.: (a) All of the volunteers here reported were between the ages of 19 and 25 , whereas Oliphant et al. used subjects from 15 to 57. years of age. (b) The amount of material used for inoculation in our group was 1 to 100 $\mathrm{ml}$. of plasma and $2 \mathrm{ml}$. of yellow fever vaccine. The dosage used by Oliphant et al. was much smaller, 0.1 to $0.16 \mathrm{ml}$. of serum and $0.5 \mathrm{ml}$. of vaccine. (c) The materials used in the present series may have contained a more virulent agent, although the mildness of the disease is somewhat against this possibility. (d) Mild transient cases, especially those without hyperbilirubinemia and demonstrable only by repeated liver function studies, may easily be overlooked. Also, in connection with the significance of the high incidence in the present group, it seems advisable to emphasize the apparent absence of other cases of jaundice among the large instutional group, with the exception of 2 cases that appeared after the disease had developed in the experimental group.

By the use of liver function tests, it has been ascertained that the onset of hepatitis, produced by an agent in serum, may be much earlier than has been generally recognized, a fact which may necessitate a revision of the current estimates of the incubation period of this disease. In 7 of the 9 volunteers, the incubation period, measured from the time of inoculation to the first manifestations of hepatitis, was 12 to 50 days, and in 6 of these, it was between 12 and 35 days. It thus appears that overt jaundice is probably a late manifestation of this malady, and one which, as indicated by 3 of the present cases, may not appear at all. The shorter incubation period directly concerns the relation of this disease to infective hepatitis. The possible etiologic identity of these diseases has been discussed repeatedly $(33,37,38)$ but no conclusions have yet been reached. In this regard, the 2 alleged forms of infective hepatitis must be briefly mentioned. (a) Single sporadic cases occurring without apparent contact with other cases of jaundice are frequently seen, and they, in turn, often do not seem to infect others with whom they are in close contact. This type of the disease apparently has. little tendency to spread. However, this or a similar disease occasionally occurs in, (b) a distinctly epidemic form. It is not yet known whether these 2 types are caused by the same or different agents. The same problem exists in connection with the relationship of the causative agent or agents of these types of hepatitis to that which is transmitted by serum. An apparently shorter incubation period, the more frequent occurrence of fever, and the contagious nature have been cited as features of the epidemic type of hepatitis that suggest a difference between its causative agent and that of serum jaundice $(2,37,38)$. It 
has been indicated by the present study that the periods of incubation may coincide. The occurrence of fever is a questionable means of distinction, for it may be present in some cases transmitted by serum and absent in some cases of infective hepatitis unrelated to serum. Furthermore, minor differences in the clinical manifestations of serum hepatitis might exist because of $(a)$ the differences in the portal of entry of the agent $(37,38),(b)$ the conditions under which the agent or agents have existed prior to entry, such as desiccation, and $(c)$ the possible presence of immune bodies in "hepatitis-producing" serum or plasma pools that might be temporarily protective. Thus, the length of the incubation period, the clinical phenomena, and the pathologic changes $(27,28)$ do not appear to provide a satisfactory basis for distinguishing between the etiological agents of these diseases. The tendency of the epidemic type of hepatitis to spread among contacts, therefore, seems to be the chief remaining point of distinction. There is as yet no unequivocal evidence that serum hepatitis is contagious, the majority of reports indicating that the disease has little tendency to spread $(2,4)$. The transmission of the agent of serum hepatitis by nasopharyngeal washings (37) suggests that contact infection may be possible, but this work has not yet been confirmed. The 2 cases reported by Propert (36) and the 2 possible cases cited herein apparently represent the only recorded instances in which contact infection may have occurred under natural circumstances. The non-contagious nature of the type of serum hepatitis that occurred in this group, in that of Oliphant et al. (2), and in the U. S. Army (1942) (4), suggests that the disease may be caused by a different strain of the same agent or by a different agent than that which causes the epidemic type of infective hepatitis. This distinction does not apply, however, to the sporadic form of infective hepatitis, for there is as yet no conclusive evidence that supports a differentiation of its causative agent from that of serum hepatitis.

Hepatitis without jaundice. Eppinger (29) has described several cases in which severe liver damage was found at autopsy in patients who had had no hyperbilirubinemia. For these cases, he used the term hepatitis sine ictero. Such ter- minal observations are quite different from the detection of hepatitis sine ictero in living subjects. Van Rooyen and Gordon (32) suspected the occurrence of hepatitis without jaundice, and Cameron (30) has stated: "other evidence from Palestine seems to show that jaundice is not essential and that a subdivision into hepatitis cum ictero and sine ictero may be justified." 12 The evidence from Palestine was not given, perhaps due to wartime restrictions, so that the data presented herein apparently provide the best evidence, to date, of hepatitis sine ictero in living subjects. As cases of this type have unquestionably been overlooked, it is probable that the available statistics afford an erroneous estimate of the true incidence of hepatitis. In addition, the recognition of hepatitis without jaundice will perhaps lead to a better understanding of the course and manifestations of the disease.

Summarizing the observations in this group, the stages of serum hepatitis may be tentatively outlined as follows:

Inoculation $\stackrel{12 \text { to } 35}{\stackrel{\text { days }}{\longrightarrow}} \begin{gathered}\text { Mild } \\ \text { hepatitis } \\ \text { without } \\ \text { jaundice }\end{gathered} \stackrel{65 \text { to } 110}{\text { days }} \begin{gathered}\begin{array}{c}\text { Hepatitis } \\ \text { with or }\end{array} \\ \begin{array}{c}\text { without } \\ \text { jaundice }\end{array}\end{gathered}$

Variations from this simple outline have been noted, and its revision may be necessary when more cases have been studied. The results of this investigation provide no direct evidence concerning the etiological agent(s) involved. Nevertheless, the demonstration of an early, nonicteric stage, and the finding that plasma taken during this stage contained the "hepatitisproducing" agent are facts which may lead to a better understanding of the epidemiology of serum hepatitis.

\section{SUMMARY}

The fact that plasma or serum may contain a transmissible agent, that is capable of producing hepatitis, has been confirmed by the results of the inoculation of 9 human volunteers. Of the

\footnotetext{
12 Following the submission of this manuscript for publication, a report by MacCallum and Bauer appeared in the Lancet $(1944,1,622)$. The occurrence, in a few inoculated volunteers, of minor symptoms in association with slight elevations of serum bilirubin insufficient to cause overt jaundice, also led them to the concept of hepatitis without jaundice.
} 
5 subjects who received intravenous injections of a pooled mumps convalescent plasma, 4 developed hepatitis with jaundice, and the 5th showed evidence of mild hepatitis without jaundice. Two men received intravenous injections of plasma that was obtained from one of the above group 23 days after his inoculation; both of them developed mild hepatitis without jaundice. The donor of this plasma developed jaundice 87 days after the plasma had been taken. Two men given subcutaneous inoculations of yellow fever vaccine developed hepatitis, one with and one without, jaundice. The incidence of hepatitis in the total group, therefore, was 100 per cent. Several of these cases would not have been detected if liver function studies had not been carried out at frequent intervals. One volunteer, who was reinoculated with the same material after recovery from the first attack, has shown no evidence of hepatitis during the $\mathbf{1 4 0}$ days that have thus far elapsed since the second inoculation.

In 6 of the 9 cases, the onset of the disease occurred from 12 to 35 days after inoculation. The contrast of this observation with previous estimates of the incubation period of this disease is discussed. Experiences with a rather large group of liver function studies are presented and their value in the study of this disease is emphasized. The advantages and limitations of certain of the individual tests are considered. Laboratory data demonstrating the occurrence of hepatitis without jaundice are presented. Observations suggesting the generalized nature of this disease are found in the report of a case in which ileitis and mesenteric adenitis were seen at laparotomy. Two cases of jaundice that may have occurred as a result of contact with one of the volunteers are briefly described. The possible relation of "serum hepatitis" to the various forms of infective hepatitis is discussed.

The authors are grateful to Dr. Charles A. Zeller, Superintendent of the Philadelphia State Hospital, through whose cooperation the volunteers were made available for this investigation. Dr. Jesse Frank and Mr. Thomas Riggs, of the laboratory of the Philadelphia State Hospital, performed some of the analyses. We also desire to acknowledge the faithful assistance of Misses Dorothy Feinberg, Anne Messer, and Arvilla Howley. Mr. Herbert Curtis and Mr. Orlando Scherling assisted in the preparation of the figures.
The men who volunteered for this investigation were: Messrs. Benjamin Candee, Jack Corbett, Herbert J. Curtis, S. Blake Ellis, Neil H. Hartman, Charles R. Lord, Robert R. Meyer, Warren D. Sawyer, and Frank E. Seeley. It is a pleasure to express our appreciation of the wholehearted collaboration of these men.

\section{BIBLIOGRAPHY}

1. Ministry of Health, Memorandum prepared by Medical Officers of the, Homologous serum jaundice. Lancet, 1943, 1, 83.

2. Oliphant, J. W., Gilliam, A. G., and Larson, C. L., Jaundice following administration of human serum. Pub. Health Rep., 1943, 58, 1233.

3. Neefe, J. R., Miller, T. G., and Chornock, F. W., Homologous serum jaundice. A review of the literature and report of a case. Am. J. M. Sc., 1944, 207, 626.

4. Circular Letter No. 95, Office of the Surgeon General, Outbreak of jaundice in the army. J. A. M. A., 1942, 120, 51. Mil. Surgeon, 1942, 91, 386.

5. Jones, T. C., and Maurer, F. D., Attempts to produce jaundice in horses by inoculation of yellow fever vaccine. Bull. U. S. Army Med. Dept., 1944, 76, 115.

6. Ward, R., and Melnick, J. L., Personal communication to the authors.

7. Malloy, H. T., and Evelyn, K. O., The determination of bilirubin with the photoelectric colorimeter. J. Biol. Chem., 1939, 119, 481.

8. Von Bergman, G. V., Zur funktionellen Pathologie der Leber. Klin. Wchnschr., 1927, 6, 776.

9. Hanger, F. M., Serological differentiation of obstructive from hepatogenous jaundice by flocculation of cephalin-cholesterol emulsions. J. Clin. Invest., 1939, 28, 261.

10. Bruger, M., Fractional cephalin-cholesterol flocculation in hepatic disease. Science, 1943, 97, 585.

11. Mirsky, I. A., and Von Brecht, R., The fractional cephalin cholesterol flocculation test. Science, 1943, 98, 499.

12. Kingsley, G. R., The direct biuret method for the determination of serum proteins as applied to photoelectric and visual colorimetry. J. Lab. \& Clin. Med., 1942, 27, 840.

13. Reinhold, J. G., Quantitative determination of free cholesterol and.cholesterol as esters without digitonin. Proc. Soc. Exper. Biol. \& Med., 1935, 32, 614.

14. Karr, W. G., Reinhold, J. G., and Chornock, F. W., Manual of Clinical Biochemistry. StevensonBrothers, Philadelphia, 1942, 62.

15. Quick, A. J., Clinical application of the hippuric acid and prothrombin tests. Am. J. Clin. Path., 1940, 10, 222.

16. Kimble, M. S., Photocolorimetric determination of vitamin $A$ and carotene in human plasma. J. Lab. \& Clin. Med., 1939, 24, 1055.

17. Wintrobe, M. M., and Landsberg, J. W., Standardized 
technique for blood sedimentation test. Am. J. M. Sc., 1935, 189, 102.

18. Waugh, T. R., and Asherman, E. G., The use of an index of hemolysis in expressing the fragility of the erythrocytes. J. Lab. \& Clin. Med., 1938, 23, 746.

19. Greenblatt, I. J., and Kaplan, G., Target cells in postvaccinal jaundice. J. A. M. A., 1943, 122, 806.

20. Godfried, E. G., Clinical tests for bilirubin in urine. Biochem. J., 1934, 28, 2056.

21. Franke, $K$., Methylenblau, ein einfaches sehr empfindliches Reagens zum Nachweis von Bilirubin. Med. Klin., 1931, 27, 94.

22. Wallace, G. B., and Diamond, J. S., Significance of urobilinogen in urine as a test for liver function with description of a simple quantitative method for its determination. Arch. Int. Med., 1925, 35, 698.

23. Watson, C. J., Studies of urobilinogen: 1 . An improved method for the quantitative determination of urobilinogen in urine and feces. Am. J. Clin. Path., 1936, 6, 458.

24. Hay-cited by Todd, J. C., and Sanford, A. H., Clinical Diagnosis by Laboratory Methods. W. B. Saunders Co., 1943, 112.

25. Klein, O., Uber den Nachweis von latenten Ikterus durch intradermale Histamininjektion (Intradermale Histaminquaddeln). Klin. Wchnschr., 1931, 10, 2032.

26. Lichtman, S. S., Disease of the liver, gallbladder and bile ducts. Lea \& Febiger, Philadelphia, 1942, p. 331.
27. Lucke, B., The pathology of fatal epidemic hepatitis. Am. J. Path., 1944, $20,471$.

28. Dible, J. H., McMichael, J., and Sherlock, S. P. V., Pathology of acute hepatitis. Lancet, 1943, 2, 402.

29. Eppinger, H., Die Leberkrankheiten, allgemeine und spezielle Pathologie und Therapie der Leber. Verlag von Julius Springer, 1937, 310.

30. Cameron, J. D. S., Infective hepatitis. Quart. J. Med., 1943, 12, 139.

31. Ford, J. C., Infective hepatitis. Lancet, 1943, 1, 675.

32. Van Rooyen, C. E., and Gordon, I., Some experimental work on infective hepatitis in M. E. F. J. Roy. Army M. Corps, 1942, 79, 213.

33. Fox, J. P., Manso, C., Penna, H. A., and Para, M., Observations on occurrence of icterus in Brazil following vaccination against yellow fever. Am. J. Hyg., 1942, 36, 68.

34. Dorland, W. A. N., The American illustrated medical dictionary. W. B. Saunders Company, 17th edition, 1936.

35. Popper, H., and Steigmann, F., The clinical significance of the plasma vitamin A level. J. A. M. A., 1943, 123, 1108.

36. Propert, A. S., Hepatitis after prophylactic serum. Brit. M. J., 1938, 2, 677.

37. Findlay, G. M., and Martin, N. H., Jaundice following yellow fever immunization: transmission by intranasal instillation. Lancet, 1943, 1, 678.

38. Editorial, Infective hepatitis and serum jaundice. Lancet, 1943, 1, 683. 